Article

\title{
In silico Designed Ebola Virus T-Cell Multi-Epitope DNA Vaccine Constructions Are Immunogenic in Mice
}

\author{
Sergei I. Bazhan*(D), Denis V. Antonets $\mathbb{D}^{D}$, Larisa I. Karpenko $\mathbb{D}^{\mathbb{D}}$, Svetlana F. Oreshkova,

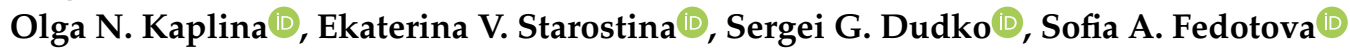 \\ and Alexander A. Ilyichev
}

State Research Center of Virology and Biotechnology “Vector”, Koltsovo, 630559 Novosibirsk Region, Russia; antonec@nprog.ru (D.V.A.); karpenko@vector.nsc.ru (L.I.K.); sv_oresh@mail.ru (S.F.O.);

okaplina@vector.nsc.ru (O.N.K.); starostina_ev@vector.nsc.ru (E.V.S.); s.g.dudko@gmail.com (S.G.D.);

hz.smoke.on.the.water@gmail.com (S.A.F.); ilyichev@vector.nsc.ru (A.A.I.)

* Correspondence: bazhan@vector.nsc.ru; Tel.: +7-383-363-47-00 (ext. 2001)

Received: 5 March 2019; Accepted: 27 March 2019; Published: 29 March 2019

check for updates

\begin{abstract}
Background: The lack of effective vaccines against Ebola virus initiates a search for new approaches to overcoming this problem. The aim of the study was to design artificial polyepitope T-cell immunogens - candidate DNA vaccines against Ebola virus and to evaluate their capacity to induce a specific immune response in a laboratory animal model. Method: Design of two artificial polyepitope T-cell immunogens, one of which (EV.CTL) includes cytotoxic and the other (EV.Th) -T-helper epitopes of Ebola virus proteins was carried out using original TEpredict/PolyCTLDesigner software. Synthesized genes were cloned in pcDNA3.1 plasmid vector. Target gene expression was estimated by synthesis of specific mRNAs and proteins in cells transfected with recombinant plasmids. Immunogenicity of obtained DNA vaccine constructs was evaluated according to their capacity to induce T-cell response in BALB/c mice using IFN $\gamma$ ELISpot and ICS. Results: We show that recombinant plasmids pEV.CTL and pEV.Th encoding artificial antigens provide synthesis of corresponding mRNAs and proteins in transfected cells, as well as induce specific responses both to CD4+ and CD8+ T-lymphocytes in immunized animals. Conclusions: The obtained recombinant plasmids can be regarded as promising DNA vaccine candidates in future studies of their capacity to induce cytotoxic and protective responses against Ebola virus.
\end{abstract}

Keywords: ebola virus disease; artificial T-cell antigens; DNA vaccine constructs; computer design; gene expression; immunogenicity

\section{Introduction}

Ebola fever or Ebola virus disease (EVD) is an acute disease resulting in high rates of mortality. It is caused by RNA-containing viruses of Filoviridae family, genus Ebolavirus. Viruses of genus Ebolavirus belong to five species with different fatality rates and serologic properties: Zaire ebolavirus, Sudan ebolavirus, Bundibugyo ebolavirus, Tai Forrest ebolavirus, and Reston ebolavirus. The first outbreaks of EVD were registered in 1976 initially in Zaire (currently the Democratic Republic of the Congo) in the Ebola river area (Zaire species, genus Ebola) and almost concurrently in Sudan (Sudan species, genus Ebola). After that, sporadic outbreaks were registered over a period of 40 years in Central Africa countries, affecting from one to several dozens or even hundreds of people. All those outbreaks were successfully and timely controlled. The Ebola fever outbreak in Western Africa in 2014-2015 was found to be significantly extensive. To eliminate it, efforts of several countries across the world were required [1]. 
The main problems the doctors met with controlling Ebola fever included the absence of a vaccine and prophylactic drugs against this disease. Despite the high fatality rate, an epidemic danger of this agent was always believed to be insignificant. Expensive development of vaccines and therapeutic drugs against rare although lethal disease in each case seemed to be unprofitable and attracted interest only due to a potential bioterrorism threat. The 2014-2015 Ebola fever outbreak claimed more than 11 thousand lives, which enforced studies on countermeasures against this infection. Currently, active studies on development of control measures against the virus are being carried out including small interfering RNA, low-molecular compounds, and antibodies [2,3], drugs based on monoclonal antibodies [3], and, certainly, vaccines. There are a number of approaches to designing vaccines against Ebola virus including DNA vaccines, subunit vaccines, as well as vaccines based on virus-like particles and viral vectors such as adenoviruses HAdV-5, HAdV-26, ChAdV-3, vesicular stomatitis virus (VSV), human cytomegalovirus, and modified vaccinia virus Ankara (MVA) [4-6]. Their protective efficacy was evaluated in non-human primate models. Furthermore, to date, several vaccines to control the virus in humans were described, i.e., rVSV-ZEBOV [7], Ad5-ZEBOV [8], GamEvac-Combi [9], and others.

The majority of developed experimental vaccines were constructed based on genetically modified viruses encoding full-length viral antigens that induce responses of both antibodies and cytotoxic T-lymphocytes (CTL) [10]. However, it should be noted that data on the protective effect of neutralizing antibodies against filoviruses obtained in studies on NHP are contradictory. It was shown that some antibodies protect animals against further infection but fail to neutralize the virus, while others neutralize the virus but fail to protect animals [11]. Consequently, the relative significance of neutralizing antibodies compared with those that can provide protection using other mechanisms (e.g., antibody-dependent cell cytotoxicity or Fc-dependent mechanisms) is still unclear. Besides this, the question deserves to be asked about the role of non-neutralizing antibodies during protection against Ebola virus, considering the well-known effect of antibody-dependent enhancement of infection [12].

A number of Ebola virus vaccine candidates develop base on glycoprotein (GP). However, antibodies induced by such GP vaccines are typically autologous and limited to the other members of the same species. In contrast, T-cell vaccines designed on the basis of conservative regions of the filovirus proteins can protect against different members of the filovirus family. It was shown that simian adenovirus- and poxvirus MVA-vectored vaccines encoding cross-filovirus immunogen provided broad immunogenicity and a solid protection of the BALB/c and C57BL/6J mice against high, lethal challenges with Ebola and Marburg viruses, two distant members of the family [5].

Another promising trend in virus T-cell vaccine design is DNA vaccine. Compared with virus-vectored vaccines, DNA vaccines demonstrate a number of advantages [13]. They are inexpensive, non-infective, and simply produced in large quantities; they can be reused since previously existing immunity is of no importance for DNA-vectors compared to viral vectors. In addition, DNA-vaccination provides the most natural way of antigen presentation by both MHC class I and class II molecules, focusing the immune response only on antigen of interest, providing long-term persistence of immunogenicity, polarizing T-helper cells toward type 1 or type 2 , and inducing protective humoral and cellular immune responses. The other important feature of DNA vaccines is the ability to put several antigens or several epitopes from different antigens in the plasmid, resulting in immunization against all of the agents; and a mixture of DNA plasmids can be used to form a broad spectrum of vaccines. At last, in vivo expression of gene of interest ensures the protein resembles the normal eukaryotic structure more closely, with accompanying post-translational modifications. The only disadvantage of DNA vaccine is their relatively low immunogenicity; thus, they require administration of several doses to achieve the desirable immunity [14]. However, this disadvantage can be evaded at present due to the strategy of intramuscular electroporation making it possible to significantly enhance DNA-vaccination efficiency [15-17]. In addition, to increase the immunogenicity of DNA vaccines it is possible to use other methods for delivery, for example, using VLPs [18] that include DNA plasmid, as well as by translating DNA vaccines into RNA vaccine format [19]. 
One of the promising trends in virus vaccine design is DNA vaccine encoding artificial polyepitope immunogens. These vaccines comprise a combination of conservative cytotoxic T-lymphocytes (CTL)and T-helper (Th)-epitopes selected from different viral proteins and combined in one molecule [20-22]. Progress in identifying T-cell epitopes, as well as understanding the mechanisms of processing and presentation of antigens by Major Histocompatibility Complex (MHC) class I and II pathways are instrumental for rational designing of artificial polyepitope vaccines inducing responses of cytotoxic (CD8+) and helper (CD4+) T-lymphocytes [20,22,23].

This study aims to design artificial polyepitope T-cell immunogens-candidate DNA vaccines against Ebola virus using computer-aided molecular design, and to study their capacity to induce a specific immune response in a laboratory animals model.

\section{Materials and Methods}

\subsection{Software}

Selection of known T-cell epitopes of Ebola viruses was carried out based on the IEDB-Immune Epitope Database (http://iedb.org) [24]. Prediction of T-cell epitopes was conducted using TEpredict software [25]. Design of polyepitope antigens was performed with PolyCTLDesigner [26]. Genes encoding target immunogens were developed using GeneDesigner software [27]; a compound of codons was optimized to achieve high expression of genes in human cells. Analysis of amino acid sequences of peptides, evaluating their conservatism, statistical analysis of obtained findings, and graph plotting were executed in statistical analysis environment R (version 3.2; https://www.R-project.org/, Vienna, Austria) [28].

\subsection{Gene Synthesis and Cloning}

Designed genes were synthesized (CJSC Eurogen, Moscow, Russia) and then cloned into pcDNA3.1 eukaryotic plasmid vector and sequenced. The obtained recombinant plasmids pEV.CTL and pEV.Th — candidate DNA vaccines against Ebola virus were used to prove the expression of designed target genes in eukaryotic cells and to assess their immunogenicity in mice of the BALB/c line.

\subsection{Evaluation of Target Gene Transcription}

Specific mRNA synthesis of target genes was evaluated in eukaryotic cells $293 \mathrm{~T}$ transfected with pEV.CTL and pEV.Th using MATra-A reagent according to the manufacturer's instruction (PromoKine, Heidelberg, Germany). Cells were cultured in Dulbecco's Modified Eagle's Medium (DMEM) with $10 \%$ FBS. $48 \mathrm{~h}$ after transfection mRNAs were isolated from cells with a kit for RNA isolation (Promega, Madison, WI, USA). Before reverse transcription all RNA samples were treated with RNase-free DNase. cDNAs were obtained by reverse transcription using RevertAid H Minus First Strand cDNA Synthesis Kit (Thermo Scientific, Berlin, Germany). Further, the obtained cDNA carried out PCR with the use of specific primers to gene EV.CTL (f $\mathrm{f}^{\mathrm{CTL}}$-AACTCAGGCACTCTTCCTGC, $\mathrm{r}^{\mathrm{CTL}}$-TCGTACCGGAATCTCAGGGT) and gene EV.Th ( $\mathrm{f}^{\mathrm{Th}}$-ACGTTGACAAGCTGAGGAGG, $\mathrm{r}^{\mathrm{Th}}$-GAGAGTCCTCAGCCCAGAGA). The amplification product was analyzed by electrophoresis in $1 \%$ agarose gel.

\subsection{Immunochemical Staining of Products of Transfected Cells}

The presence of target proteins in eukaryotic cells 293T transfected with pEV.CTL and pEV.Th was detected through immunostaining. Cell transfection was carried out using MATra-A reagent according to the manufacturer's instruction (PromoKine, Germany). Cells were cultured in DMEM medium with $10 \%$ FBS. $32 \mathrm{~h}$ after transfection cells were washed in phosphate buffer solution (PBS), fixed in a mix of ice methanol/acetone $(1: 1)$ at $40{ }^{\circ} \mathrm{C}$ for $30 \mathrm{~min}$, and then washed in PBS again. The expression products of EV.CTL and EV.Th gene were detected in immunochemical staining. Staining was carried out using antibodies MAT 29F2/30A6 (JSC Vector-Best, Novosibirsk, Russia) 
to marker epitope EPFRDYVDRFYKTL being a part of all constructs, and using conjugate of rabbit antibodies to mice IgG with horseradish peroxidase. When staining, 3.3'-Diaminobenzidine was used as substrate.

\subsection{Ethics Statement}

All experimental procedures in mice were made to minimize animal suffering and carried out in line with the principles of humanity described in the relevant Guidelines of the European Community and Helsinki Declaration. The protocols were approved by the Institutional Animal Care and Use Committee (IACUC) affiliated with State Research Center of Virology and Biotechnology "Vector" (Permit Number: SRC VB “Vector”/10-05.2016).

\subsection{Immunization of Experimental Animals Ethics Statement}

When immunizing, we used 5-6-week-old BALB/c mice (female) of weight 16-18 g from the State Research Center of Virology and Biotechnology Vector vivarium. Animals were divided into four groups with 5-10 mice in each group including (1) pE-CTL+pE-Th-mice immunized with a mix of DNA-vaccine pEV.CTL and pEV.Th encoding CTL- and Th-epitopes of Ebola virus, respectively; (2) pE-CTL-mice immunized with DNA plasmid pEV.CTL encoding CTL-epitopes of Ebola virus; (3) pDNA3.1 - mice immunized with vector plasmid pDNA3.1 (negative control); and (4) —intact non-immunized animals to whom phosphate buffered saline was inoculated (PBS) (pH 7.6) (negative control). Mice were immunized three times intramuscularly with $100 \mu \mathrm{g}$ DNA vaccine pEV.CTL or pEV.CTL + pEV.Th at 2-week intervals. An equivalent dose of pcDNA3.1 vector plasmid was used for mice from the control group. Two weeks after the last immunization, spleens were removed in animals and splenocytes were isolated to analyze T-cell immune response.

\subsection{Detection of T-Cell Immune Response Using IFN $\gamma$ ELISpot and Intracellular Cytokine Staining (ICS) Assay}

Enzyme-Linked ImmunoSpot (ELISpot) and intracellular cytokine staining (ICS) assays were used to characterize the immune response of mice after immunization with DNA vaccines. Stimulation of splenocytes was carried out using a mix of synthetic peptides (KFINKLDALH, NYNGLLSSI, PGPAKFSLL, YFTFDLTALK, EYLFEVDNL, LFLRATTEL, and LYDRLASTV) from the compound of the designed antigens. Peptides were synthesized by Synpeptide Co., Ltd. (Shanghai, China) with $>80 \%$ purity. Analysis of IFN $\gamma$ ELISpot was performed with Mouse IFN- $\gamma$ ELISPOT Set (BD, cat 551083, San Diego, CA, USA) according to the manufacturer's instruction and as previously described [29]. To stimulate splenocytes, we used a mix of peptides at concentration $20 \mu \mathrm{g} / \mathrm{mL}$ of each peptide to $1 \times 10^{6}$ cells followed by co-cultivation for $24 \mathrm{~h}$. IFN $\gamma$-producing cells were calculated using an ELISpot-analyzer (Zeiss, Germany). ICS was performed according to the standard protocol of BD Biosciences as previously described [30]. To stimulate splenocytes, we used a mix of peptides at concentration $20 \mu \mathrm{g} / \mathrm{mL}$ of each peptide to $1 \times 10^{6}$ cells and incubated for $20 \mathrm{~h}$ at $37^{\circ} \mathrm{C}$ and $5 \%$ $\mathrm{CO}_{2}$ and additionally for $5 \mathrm{~h}$ with Brefeldin A. Cells were washed with PBS and permeabilized with Cytofix/Cytoperm ${ }^{\mathrm{TM}}$ Plus Fixation/Permeabilization Kit (BD Biosciences, San Diego, CA, USA). When staining, the following monoclonal antibodies were used: PerCP Rat Anti-Mouse CD4, FITC Rat Anti-Mouse CD8a, PE Hamster Anti-Mouse CD3 $\varepsilon$, and APC Rat Anti-Mouse IFN- $\gamma$ (BD Pharmingen, San Diego, CA, USA). The samples were analyzed using flow cytometer FACSCalibur (Becton Dickinson, San Jose, CA, USA) and Cell Quest software.

\subsection{Statistical Analysis}

Statistical analysis of the obtained results was carried out with the $\mathrm{R}$ software environment for statistical analysis (version 3.2; https://www.R-project.org/). To evaluate the significance of the differences among the groups, the Kruskal-Wallis test was applied. Pair-wise distribution comparison 
of the analyzed indices in the experimental and control groups was conducted using one-sided Mann-Whitney test. When multiple testing, FDR procedure was performed to correct $p$-values.

\section{Results and Discussion}

\subsection{Strategies to Design Polyepitope T-Cell Antigens}

To stimulate response of CD8+ T-lymphocytes, viral antigens must be presented to CTL precursors not as full-length molecules, but as short peptides (8-12 amino acid residues) in complex with MHC class I molecules. These epitopes are formed from endogenously synthesized viral antigens in the result of proteasome-mediated processing and then are transferred to ER lumina by means of a transporter associated with antigen processing (TAP) proteins where it binds to emerged MHC class I molecules (see for review [31,32]). Since proteasome-mediated processing functions for antigens synthesized intracellularly, a vaccine inducing T-cell response may be designed as DNA vaccine because in this case the CTL vaccine epitopes are presented in the most natural way-through MHC class I-dependent antigen presentation pathway [33].

Unlike stimulation of CTLs, while stimulating CD4+ T-lymphocytes-helpers response, antigen should be presented to those cells in complex with MHC class II molecules. Usually, antigen processing and presentation occurs for extracellular antigens which are delivered in cells via endocytosis and phagocytosis. In this case, antigen processing takes place in the lysosome.

Thus, when designing artificial polyepitope T-cell immunogens capable of inducing responses of CD4+ and CD8+ T-lymphocytes to all epitopes it comprises, it is necessary to provide efficient proteasome- and/or lysosome-mediated processing of the expression product of the target gene by MHC class I and II pathway.

Different strategies can help achieve this goal:

(1) To combine epitopes in the compound of poly-CTL-epitope construct one may use spacer sequences comprising sites of proteasomal cleavage [34-36] and/or motifs for binding to TAP [37,38].

(2) To combine epitopes in the compound of poly-Th-epitope construct one may use motif [KR][KR] which is a cleavage site for a number of lysosomal cathepsins involved in antigen processing [39,40].

(3) To direct polyepitope immunogen to proteasome and to present CTL-epitopes to CD8+ T-lymphocytes by MHC class I pathway, genetic binding of ubiquitin sequence to its $\mathrm{N}$ - or C-terminus is typically used [41].

(4) To degrade polyepitope immunogen and present released Th-epitopes to CD4+ T-lymphocytes by MHC class II pathway, genetic binding of sequence of LAMP-1 (Lysosomal-associated membrane protein 1) tyrosine motif to its $\mathrm{C}$-terminus is typically used to direct polyepitope immunogen from the secretory pathway to the lysosome [42-45].

In our study, two artificial polyepitope T-cell immunogens were designed, one of which comprises cytotoxic (CTL) and the other-T-helper (Th) epitopes identified in Ebola virus proteins GP, VP24, VP30, VP35, L, VP40, and NP (Figure 1). Previously we showed that adding ubiquitin to N-terminus of polyepitope antigen induces CD8+ T-cell response more efficiently as compared to adding the signal peptide and the LAMP-1 C-terminal fragment [30]. Therefore, we added N-terminal ubiquitin to the final poly-CTL-epitope construct, and poly-Th-epitope immunogen was designed using N-terminal signal peptide and LAMP-1 C-terminal fragment. N-terminal signal peptide should direct the polyepitope to the endoplasmic reticulum (ER), and C-terminal fragment of LAMP-1 should redirect the polyepitope from the secretory pathway to the lysosome. 


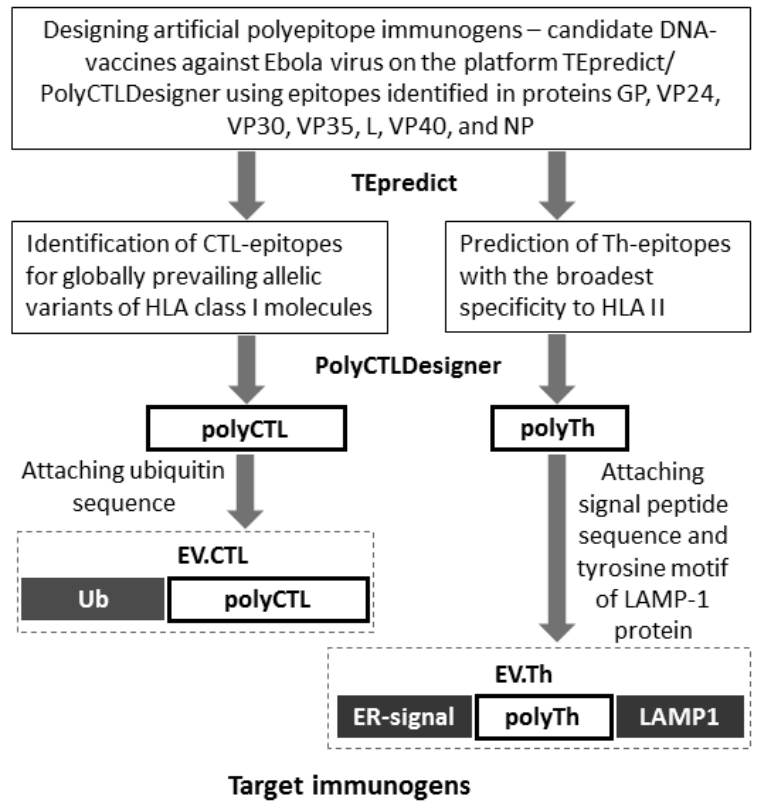

Figure 1. Designing artificial polyepitope antigens of Ebola virus.

\subsection{Design of Artificial Poly-CTL-Epitope Antigen of Ebola Virus}

For the purposes of designing poly-CTL-epitope antigen (EV.CTL), we used Immune Epitope Database (http://iedb.org) [24] to select known T-cell epitopes and peptide fragments of antigens of different Ebola virus strains with an experimentally verified capacity to bind to different allomorphs of MHC molecules. In total, at the time of antigen designing (2016) the database contained information on 1134 unique peptides from 65 antigens of 16 Ebola virus strains verified for their capacity to bind to 60 allomorphs of MHC class I molecules (56 Human Leukocyte Antigen (HLA) allelic variants). To analyze conservation of peptides, we used 14,556 amino acid sequences from NCBI ProteinBank (ncbi.nlm.nih.gov/protein) belonging to different Ebola viruses (Zaire ebolavirus, Sudan ebolavirus, Bundibugyo ebolavirus, Tai Forrest ebolavirus, and Reston ebolavirus). We considered peptides with experimentally verified cytotoxic activity. Furthermore, when designing target immunogens, we selected those with sufficiently high binding affinity to different HLA class I molecule variants ( $\mathrm{pIC50}>6.3$ ).

After that, we selected peptides identified at least in 1000 known viral sequences and interacting with at least two allelic HLA molecule variants. In total, we selected 44 peptides which cumulatively were restricted by 34 allelic HLA class I molecule variants including the most globally widespread ones (Table 1). It is known that optimally selected epitopes restricted by ten different HLA class I alleles cover virtually the entire population of any geographic region [46,47].

Based on the selected T-cell epitopes, we designed EV.CTL poly-CTL-epitope antigen using TEpredict/PolyCTLDesigner software we developed earlier $[25,26]$ that we regard as a universal platform for rational design of polyepitope immunogens-candidate DNA vaccines to induce T-cell immunity to infectious as well as oncological diseases. PolyCTLDesigner enables us to select a minimal set of epitopes with known or predicted specificity to different allelic variants of MHC class I molecules covering a selected repertoire of HLA alleles with a preset degree of redundancy. After that, PolyCTLDesigner predicts binding affinity to TAP for the selected set of known or predicted epitopes using a model developed by Peters et al. [48] and when required adds TAP-specific amino acid residues (no more than three) to epitope $\mathrm{N}$-terminus to optimize binding. 
Table 1. Predicted CD8+ cytotoxic T-lymphocytes (CTL)-epitopes in the sequences of Ebola virus proteins (antigens).

\begin{tabular}{|c|c|c|c|c|}
\hline No. & Epitope & Antigen & Epitope Frequency & HLA Class I Alleles \\
\hline 1 & ARLSSPIVL & $\mathrm{L}$ & 1741 & 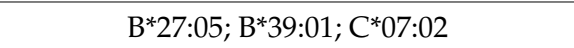 \\
\hline 2 & EYAPFARLL & NP & 1764 & $\mathrm{~A} * 24: 03 ; \mathrm{A} * 24: 02$ \\
\hline 3 & FAEGVVAFL & GP & 3881 & 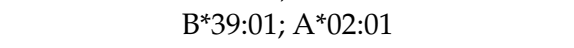 \\
\hline 4 & FIYFGKKQY & $\mathrm{L}$ & 1737 & 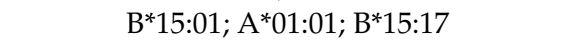 \\
\hline 5 & FLLQLNETI & GP & 3862 & 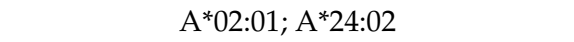 \\
\hline 6 & FLSFASLFL & NP & 1755 & $\mathrm{~A}^{*} 02: 01 ; \mathrm{A}^{*} 24: 02 ; \mathrm{C}^{*} 03: 03$ \\
\hline 7 & FPRCRYVHK & GP & 3956 & 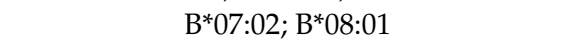 \\
\hline 8 & FRLMRTNFL & NP & 1767 & $B^{* 39: 01 ; B^{*} 08: 01 ; C^{*} 06: 02}$ \\
\hline 9 & FRYEFTAPF & $\mathrm{L}$ & 1744 & 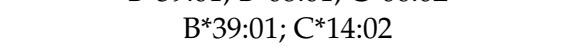 \\
\hline 10 & FTPQFLLQL & GP & 3868 & 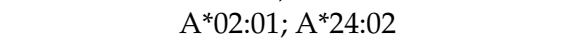 \\
\hline 11 & FVHSGFIYF & $\mathrm{L}$ & 1739 & 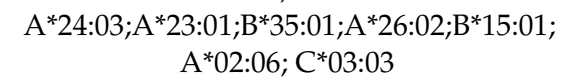 \\
\hline 12 & GHMMVIFRL & NP & 1768 & $B^{* 39: 01 ;} A^{* 02: 01 ;} A^{* 24: 02}$ \\
\hline 13 & GQFLSFASL & NP & 1753 & $B^{*} 15: 01 ; B^{*} 27: 05$ \\
\hline 14 & GYLEGTRTL & $\mathrm{L}$ & 1748 & $A * 24: 03 ; A * 23: 01$ \\
\hline 15 & HMMVIFRLM & NP & 1768 & $A^{* 02: 01 ;} A^{* 24: 02}$ \\
\hline 16 & HPLARTAKV & NP & 1766 & $B * 07: 02 ; B * 51: 01$ \\
\hline 17 & IISDLSIFI & $\mathrm{L}$ & 1713 & $A^{*} 02: 01 ; A^{*} 69: 01$ \\
\hline 18 & ILMNFHQKK & NP & 1711 & $A^{*} 03: 01 ; A^{* 11: 01}$ \\
\hline 19 & IMYDHLPGF & VP35 & 1737 & $B * 58: 01 ; C^{* 12: 03}$ \\
\hline 20 & KQIPIWLPL & VP40 & 1766 & $B * 40: 01 ; B * 27: 05$ \\
\hline 21 & KVYWAGIEF & VP24 & 1702 & 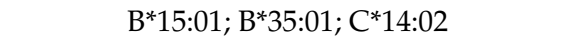 \\
\hline 22 & LANETTQAL & GP & 1242 & $B^{*} 07: 02 ; B^{*} 35: 01 ; C^{*} 03: 03$ \\
\hline 23 & LANPTADDF & VP30 & 1686 & $B^{*} 35: 01 ; B^{*} 58: 01$ \\
\hline 24 & LPQYFTFDL & VP40 & 1763 & $\mathrm{~B}^{*} 07: 02 ; \mathrm{B}^{* 35: 01}$ \\
\hline 25 & LSDLCNFLV & VP24 & 1725 & $A^{*} 01: 01 ; C^{*} 05: 01$ \\
\hline 26 & MMVIFRLMR & NP & 1768 & $A^{*} 03: 01 ; A^{* 11: 01}$ \\
\hline 27 & NFFHASLAY & $\mathrm{L}$ & 1750 & 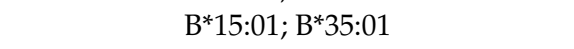 \\
\hline 28 & QFLSFASLF & NP & 1755 & $A * 24: 03 ; A * 24: 02$ \\
\hline 29 & RLASTVIYR & GP & 3947 & $A^{*} 03: 01 ; A^{* 31: 01}$ \\
\hline 30 & RLMRTNFLI & NP & 1766 & $\mathrm{~A}^{*} 02: 01 ; \mathrm{A}^{* 24: 02}$ \\
\hline 31 & RTFSILNRK & GP & 1207 & $A^{*} 03: 01 ; A^{* 11: 01 ;} A^{* 31: 01}$ \\
\hline 32 & RTSFFLWVI & GP & 3802 & $\mathrm{~A}^{* 02: 01 ;} \mathrm{A}^{* 24: 02}$ \\
\hline 33 & RVPTVFHKK & VP30 & 1684 & $A * 03: 01 ; A * 31: 01$ \\
\hline 34 & SFASLFLPK & NP & 1756 & $A * 03: 01 ; A * 11: 01$ \\
\hline 35 & TLASIGTAF & $\mathrm{L}$ & 1743 & $\mathrm{~B}^{*} 15: 01 ; \mathrm{B}^{* 35: 01}$ \\
\hline 36 & TPVMSRFAA & $\mathrm{L}$ & 1738 & $B * 07: 02 ; B * 35: 01$ \\
\hline 37 & TRSFTTHFL & $\mathrm{L}$ & 1747 & 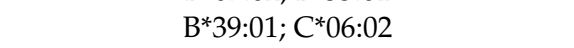 \\
\hline 38 & TTIGEWAFW & GP & 3824 & $A^{* 24: 02 ;} B^{* 58: 01 ;} A^{* 68: 23} ; A^{* 32: 15 ;} A^{* 32: 07}$ \\
\hline 39 & TVAPPAPVY & NP & 1684 & $A^{*} 11: 01 ; B^{*} 35: 01$ \\
\hline 40 & VLYHRYNLV & $\mathrm{L}$ & 1746 & $A^{* 02: 01 ;} A^{* 03: 19}$ \\
\hline 41 & VQLPQYFTF & VP40 & 1763 & $B^{*} 15: 01 ; A^{*} 24: 03$ \\
\hline 42 & YLEGHGFRF & NP & 1739 & $A * 02: 01 ; A * 24: 02$ \\
\hline 43 & YQGDYKLFL & NP & 1705 & $A^{*} 02: 01 ; A^{*} 24: 02$ \\
\hline 44 & YSGNIVHRY & $\mathrm{L}$ & 1750 & $A^{* 01: 01 ; B * 58: 01}$ \\
\hline
\end{tabular}

At the next step, PolyCTLDesigner analyzes all possible matchings of the selected peptides and detects the optimal spacer sequence for each pair providing an appropriate cleavage of epitopes with a release of proximal peptide C-terminus. To predict proteasomal and/or immunoproteasomal cleavage, PolyCTLDesigner uses models developed by Toes, et al. [49].

When analyzing matchings of epitopes, PolyCTLDesigner forms a direct graph where nodes denote epitopes and ribs correspond to acceptable matchings. Each rib has a relevant weight vector characterized by effective proteasomal cleavage, spacer length, and a number of predicted non-target epitopes at the joint. At the final stage, the software designs the optimal resultant of polyepitope immunogen sequence determined as a full simple way in the formed graph with the least length (weight). 
In this study, we used PolyCTLDesigner to predict binding affinity of the selected peptides (Table 1) to TAP; when required software added alanine residue to peptides N-terminus to enhance interaction efficiency. Poly-CTL-epitope fragment of EV.CTL was designed using a degenerated spacer motif [ARSP][DLIT][LGA][VKA] with optimization of proteasomal cleavage and $10 \%$ exactness of proteasomal filter.

To test the immunogenicity of the designed vaccine construct in mice using ELISpot and ICS, we selected seven additional peptides with proven ability to induce cytotoxic response of T-lymphocytes in BALB/c mice: KFINKLDALH, NYNGLLSSI, PGPAKFSLL, YFTFDLTALK, EYLFEVDNL, LFLRATTEL, and LYDRLASTV. Based on the selected peptides, mouse polyepitope fragment included at C-terminus of the polyepitope construct was designed with PolyCTLDesigner. To verify synthesis of the designed antigen in transfected cells, we included C-terminal marker epitope EPFRDYVDRFYKTLR of p24 HIV-1 protein recognized by monoclonal antibodies $29 \mathrm{~F} 2$ in the final construct.

Designed amino acid sequence appears as follows (mouse epitopes are italicized):

MMVIFRLMR-ADLS-GHMMVIFRL-KK-VQLPQYFTF-ADLS-KQIPIWLPL-RK-EYAPFA RLL-RVPTVFHKK-FIYFGKKQY-R-VLYHRYNLV-ADL-YQGDYKLFL-AFPRCRYVHK-ATP VMSRFAA-AFAEGVVAFL-KVYWAGIEF- $\mathbf{R}-$ TVAPPAPVY-TLASIGTAF- - -TTIGEWAFWRK-LANETTQAL-FLLQLNETI-R-FVHSGFIYF-K-IISDLSIFI-R-NFFHASLAY-RR-LAN PTADDF-K-ILMNFHQKK-ADLS-FTPQFLLQL-YSGNIVHRY-ADLA-RTSFFLWVI-RTF

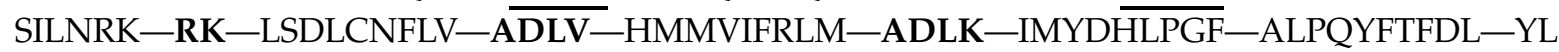
EGHGFRF-R-FLSFASLFL- $\overline{\mathbf{R}-\mathrm{TRSFTTHFL}-\mathrm{RLMRTNFLI}-A D G-F R L M R T N F L-R-G Q F L S F A ~}$ SL-R-SFASLFLPK-RLASTVIYR-ARLSSPIVL-AHPLARTA KV-QFLSFASLF-R-GYLEGTRTL -R-FRYEFTAPF-KK-YFTFDLTALK-EYLFEVDNL- $\mathbf{R}-P G P A K F S L L-\boldsymbol{R} \boldsymbol{K}-$ LFLRATTEL-RKNYNGLLSSI-R-LYDRLASTV-R-KFINKLDALH-SGSG-EPFRDYVDRFYKTLR

The length of the designed polyepitope EV.CTL is 547 amino acids; a share of spacer sequences is $12.76 \%$. To target polyepitope immunogen into proteasome, we added ubiquitin sequence to $\mathrm{N}$-terminus of the final poly-CTL-epitope construct.

\subsection{Design of Poly-Th-Epitope Ebola Virus}

To achieve the most efficient induction of T-cell immune response, one should induce not only responses of CD8+ but also CD4+ T-lymphocytes; therefore, in the following steps, we constructed poly-Th-epitope fragment (EV.Th). We used Th-epitopes predicted for humans and showing the broadest specificity regarding HLA class II molecules. For the purpose, TEpredict [25] predicted Th-epitopes in Ebola virus proteins. PolyCTLDesigner [26] was used to select eight fragments of the length of 35-40 amino acid residues comprising the most of the Th-epitopes with the broadest specificity regarding different HLA class II allomorphs. N-terminus of the selected peptides was extended up to 5 amino acid residues as compared to the beginning of the first epitope, and C-terminus-up to 5 amino acid residues as compared to the end of the last epitope (Table 2).

Additionally included at C-terminus of the construct: universal Th-epitope PADRE (PAn DR Epitope)—AKFVAAWTLKAAA; marker epitope EPFRDYVDRFYKTLR of p24 HIV-1 protein recognized by monoclonal antibodies 29F2, and a C-terminal fragment of LAMP-1 proteinRKRSHAGYQTI. According to the literature, adding the signal peptide concurrently with LAMP-1 C-terminus fragment to the target antigen raises the level of CD4+ T-lymphocyte response significantly [50-53]. As a signal peptide, we selected the sequence of an N-terminal fragment of Ebola virus surface glycoprotein comprising MGVTGILQLPRDR leader peptide. Using the SignalP server [54] we predicted that the leader peptide in the designed artificial polypeptide is functional and should efficiently split out. Poly-Th-epitope antigen EV.Th was designed using K/R-K/R spacer sequences that form cleavage sites by lysosomal cathepsins $[39,40]$ :

MGVTGILQLPRDR-FKRTSFFLWVIILFQRTFSIPLGVIHNSTLQVSDVDKL-RR-TNTNHFN MRTQRVKEQLSLKMLSLIRSNILKFINKLDA-RR_LTLDNFLYYLTTQIHNLPHRSLRILKPTFK 
HASVMSRL-RR-TQTYHFIRTAKGRITKLVNDYLKFFLIVQALKHNGTWQAE-RR-WDRQ SLIMFITAFLNIALQLPCESSAVVVSGLRTLVPQSD-RR-SSAFILEAMVNVISGPKVLMKQIPIW LPLGVADQKTYSF-RR-QYPTAWQSVGHMMVIFRLMRTNFLIKFLLIHQGMHMVAGH-RR-ES ADSFLLMLCLHHAYQGDYKLFLESGAVKYLE-RR-AKFVAAWTLKAAA -SGSG-EPFRDY VDRFYKTLR-SGSG-RKRSHAGYQTI

MGVTGILQLPRDR—signal peptide; AKFVAAWTLKAAA-PADRE epitope; EPFRDYVDRF YKTLR-marker epitope; RKRSHAGYQTI-C-terminal fragment of LAMP-1 protein.

Table 2. Predicted CD4+ T-helper (Th)-epitopes in the sequences of Ebola virus proteins (antigens) *.

\begin{tabular}{|c|c|c|c|c|}
\hline Peptide & Protein & Fragment & $\begin{array}{c}\text { Number of } \\
\text { HLA-DR } \\
\text { Allomorphs }\end{array}$ & $\begin{array}{c}\text { Number } \\
\text { of } \\
\text { Epitopes }\end{array}$ \\
\hline FKRTSFFLWVIILFQRTFSIPLGVIHNSTLQVSDVDKL & GP & $14-51$ & 48 & 11 \\
\hline TNTNHFNMRTQRVKEQLSLKMLSLIRSNILKFINKLDA & VP24 & $129-166$ & 49 & 8 \\
\hline LTLDNFLYYLTTQIHNLPHRSLRILKPTFKHASVMSRL & $\mathrm{L}$ & $1486-1523$ & 50 & 5 \\
\hline TQTYHFIRTAKGRITKLVNDYLKFFLIVQALKHNGTWQAE & $\mathrm{L}$ & $2111-2150$ & 48 & 10 \\
\hline WDRQSLIMFITAFLNIALQLPCESSAVVVSGLRTLVPQSD & VP30 & $230-269$ & 47 & 8 \\
\hline SSAFILEAMVNVISGPKVLMKQIPIWLPLGVADQKTYSF & VP40 & $70-108$ & 42 & 8 \\
\hline QYPTAWQSVGHMMVIFRLMRTNFLIKFLLIHQGMHMVAGH & NP & $186-225$ & 50 & 13 \\
\hline ESADSFLLMLCLHHAYQGDYKLFLESGAVKYLE & NP & $68-100$ & 47 & 5 \\
\hline
\end{tabular}

*-Table demonstrates peptide sequence, antigen name, the beginning and the end of the selected peptide, the number of HLA class II allomorphs interacting with a fragment, the number of Th epitopes predicted in a fragment.

3.4. Designing Artificial Genes and Producing Recombinant Plasmids_Candidate DNA Vaccines Against Ebola Virus Encoding Polyepitope Immunogens of Ebola Virus

Artificial genes encoding EV.CTL and EV.Th-immunogens of Ebola virus were designed using GeneDesigner software [27]. Reverse translation of amino acid sequences was conducted considering the frequency of codons in humans [55]. Kozak sequence (CCGCCACC) is located ahead of ATG initiating codon. At the end of the encoding sequence, three stop-codons (TAGTGATGA) were added. Designed genes-EV.CTL and EV.Th were synthesized and cloned in pcDNA 3.1 vector plasmid. As the result, we constructed two recombinant plasmids pEV.CTL and pEV.Th—candidate DNA vaccines against Ebola virus.

\subsection{Analysis of Target Gene Expression}

The genes expression of DNA vaccines was evaluated with two methods: specific mRNA synthesis assay and immunostaining of the transfected cells. To evaluate synthesis of specific mRNA, we isolated total RNA from 293T cells transfected with plasmids pEV.CTL and pEV.Th and obtained cDNA in RT. The obtained cDNA was used to carry out PCR using pairs of primers $\left(\mathrm{f}^{\mathrm{CTL}}, \mathrm{r}^{\mathrm{CTL}}\right)$ and $\left(\mathrm{f}^{\mathrm{Th}}, \mathrm{r}^{\mathrm{Th}}\right)$ to genes EV.CTL and EV.Th, respectively.

The results in Figure 2 demonstrate that the sizes of the amplified fragments correspond to the theoretically calculated sizes of amplification products, i.e., $891 \mathrm{bps}$ for EV.CTL gene and $495 \mathrm{bps}$ for EV.Th gene. Similar PCR fragments were obtained when using initial target plasmids pEV.CTL and pEV.Th (positive control) as a matrix. The findings indicate presence of specific mRNA in the total cell RNA fraction. 


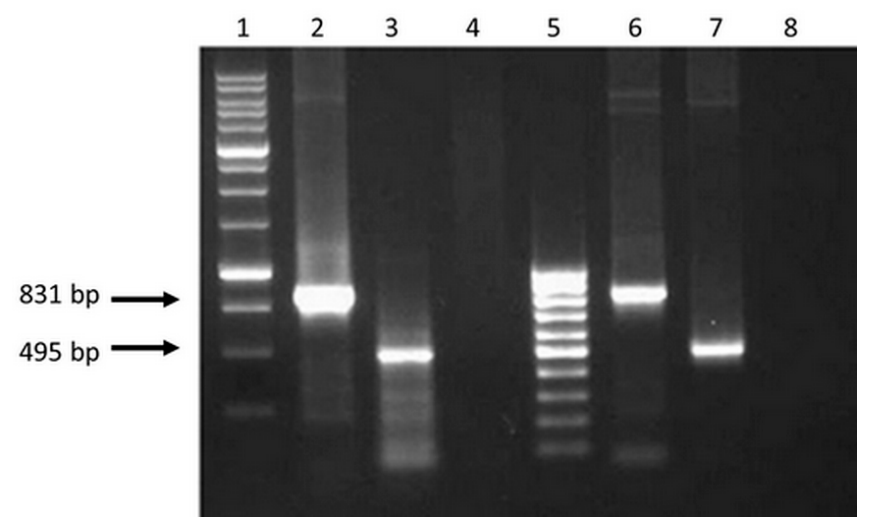

Figure 2. Electrophoregram on 1\% agarose gel of PCR products: 1 - Molecular weight marker (M12, SibEnzyme); 2 and 3-PCR fragments of 831 and 495 bps obtained using cDNA as a matrix with primers (fCTL, rCTL) and (fTh, rTh), respectively; 4 and 8 -The results of PCR with primers (fCTL, rCTL) and (fTh, rTh) and total RNA isolated from 293T cells transfected with plasmids pEV.CTL and pEV.Th, respectively (without reverse transcription; control for the absence of target plasmids in isolated samples of total RNA); 5-Molecular weight marker (M15, SibEnzyme); 6 and 7-PCR fragments obtained using plasmids pEV.CTL and pEV.Th as a matrix, respectively (positive control).

Immunohistochemical staining of cells transfected with pEV.CTL and pEV.Th plasmids was evaluated using MAT 29F2/30A6 antibodies to EPFRDYVDRFYKTL marker epitope, included in all constructs. The results depicted in Figure 3 demonstrate the presence of specific proteins. The findings confirm the expression of the target genes both at the level of transcription and translation.

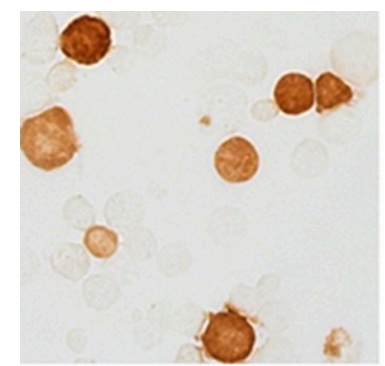

(a)

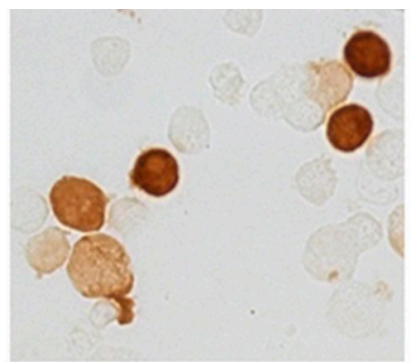

(b)

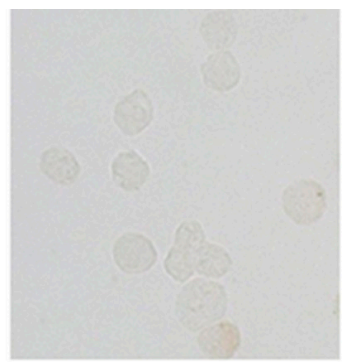

(c)

Figure 3. Evidence of genes expression in cells transfected with plasmids pEV.CTL and pEV.Th by immunohistochemical staining. (a) 293T-cells transfected with pEV.CTL plasmid. (b) 293T-cells transfected with $\mathrm{pEV.Th}$ plasmid. (c) 293T-cells transfected with pcDNA3.1 vector plasmid.

\subsection{Immunogenicity Study of DNA-Vaccine Constructs Encoding Multiple T-Cell Epitopes of Ebola Virus}

Immunogenicity of the target DNA vaccine constructs was evaluated regarding their capacity to induce a T-cell response in BALB/c mice 14 days after the third immunization. The level of T-cell immune response was detected using IFN $\gamma$-ELISpot and ICS.

ELISpot results (Figure 4) demonstrate that the induction of specific response was registered in both experimental groups [pE-CTL $+\mathrm{pE}-\mathrm{Th}]$ and [pE-CTL], especially in the animal group immunized with a mix of target DNA vaccine constructs [pE-CTL $+p E-T h]$. Significant differences from both negative controls were observed only in [pE-CTL+pE-Th] group (Table 3).

The capacity of vaccine constructs to induce IFN $\gamma$-producing CD4+ and CD8+ T-cells was tested by ICS after stimulating splenocytes with specific peptides. The results of ICS (Figure 5) revealed that statistically significant difference from control (Table 4) was demonstrated by IFN $\gamma$-producing CD8+ T-lymphocytes in animal groups immunized both with pEV.CTL and a mix (pEV.CTL + pEV.Th) DNA vaccines as well as by IFN $\gamma$-producing CD4+ T-helpers in the group immunized with only a 
mix of vaccine constructs (pEV.CTL + pEV.Th). The maximal responses of IFN $\gamma$-producing CD8+ T-lymphocytes $(p=0.024)$ and CD4 + T-cells $(p=0.012)$ were registered in the animal group immunized with a mix of vaccine constructs. This is believed to be caused by the synergistic effect of CD8+ and CD4+ T-lymphocytes.

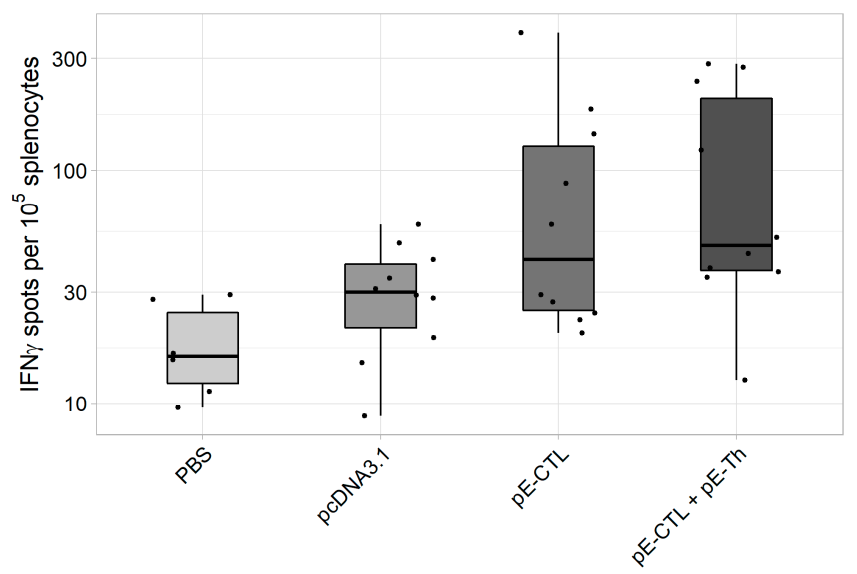

Figure 4. The results of IFN $\gamma$-producing T-cell count in IFN $\gamma$-ELISpot assay in BALB/c mice immunized with DNA-vaccine constructs encoding target immunogens ( $n=6$ for phosphate buffer solution (PBS) control group and $\mathrm{n}=10$ for the other groups). The figure represents spot count (i.e., IFN $\gamma$-producing T-cells) in different experimental and control animal groups.

Table 3. Results of statistical data analysis in ELISpot.

\begin{tabular}{cccc}
\hline Animal Groups & Phosphate Buffer Solution (PBS) & pcDNA3.1 & pE-CTL \\
\hline pcDNA3.1 & 0.070 & - & - \\
pE-CTL & 0.029 & 0.148 & - \\
pE-CTL + pE-Th & 0.009 & 0.0296 & 0.264 \\
\hline
\end{tabular}

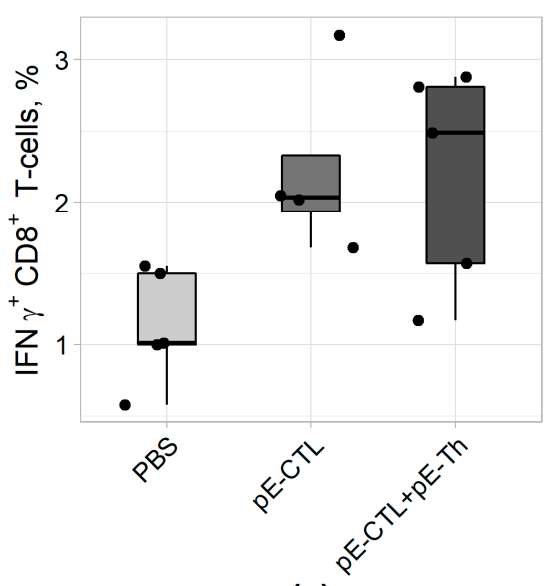

(a)

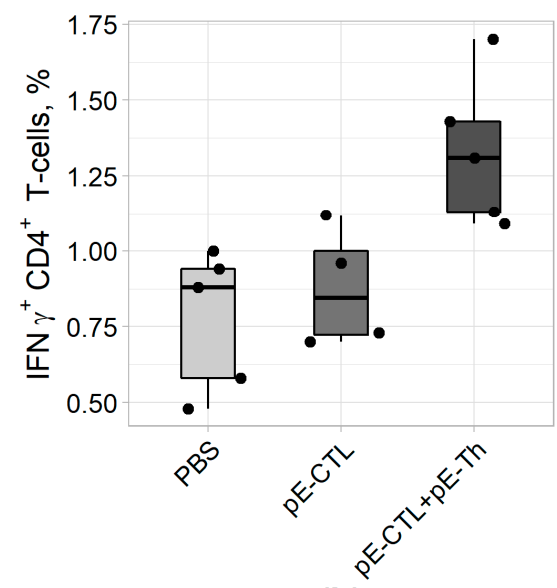

(b)

Figure 5. The results of IFN $\gamma$-producing CD4+ (A) and CD8+ (B) T-cell count using intracellular cytokine staining (ICS) approach in BALB/c mice immunized with DNA vaccine constructs encoding target immunogens $(n=5)$.

To design the target antigens, we used PolyCTLDesigner software that we had developed for rational design of artificial polyepitope vaccine constructs [26]. It enables us to calculate amino acid sequence of polyepitope antigen by detecting the best spacer sequences for each pair of epitopes and optimal relative positions of epitopes in the construct considering state-of-the-art knowledge about the specificity of proteasomal processing of antigens and interaction between peptides and TAP. 
The findings revealed that the designed artificial DNA vaccine constructs encoding CTL and Th-epitopes of Ebola virus antigens provide expression of the target genes, as well as induce virus-specific responses of CD4+ and CD8+ T-lymphocytes in immunized mice.

Table 4. Statistical analysis results obtained using intracellular cytokine staining (ICS).

\begin{tabular}{ccccc}
\hline \multirow{2}{*}{ Animal Groups } & \multicolumn{2}{c}{ CD8+IFN $\gamma+$} & \multicolumn{2}{c}{ CD4+IFN $\gamma+$} \\
\cline { 2 - 5 } & PBS & pE-CTL & PBS & pE-CTL \\
\hline pE-CTL & 0.024 & - & 0.278 & - \\
pE-CTL+pE-Th & 0.024 & 0.635 & 0.012 & 0.024 \\
\hline
\end{tabular}

\section{Conclusions}

Our original developed TEpredict/PolyCTLDesigner software was used in the study to predict cytotoxic and T-helper epitopes in a compound of seven Ebola virus proteins (GP, VP24, VP30, VP35, L, VP40, and NP) and to design two polyepitope immunogens EV.CTL and EV.Th on the base of those epitopes. Recombinant plasmids, candidate DNA vaccines against Ebola virus encoding the designed antigens, were obtained. We show that the designed DNA vaccine constructs provide a synthesis of corresponding mRNA and proteins in a eukaryotic cell culture, as well as induce statistically significant responses both of CD4+ and CD8+ T-lymphocytes in immunized animals, and consequently are promising candidates for further studies of their capacity to induce cytotoxic and protective responses.

Author Contributions: Conceptualization, S.I.B., A.A.I. and D.V.A.; Methodology, S.I.B., L.I.K. and D.V.A.; software, D.V.A.; validation, S.I.B., L.I.K., O.N.K. and D.V.A.; Formal analysis, D.V.A.; Investigation, S.F.O., O.N.K., E.V.S., S.G.D. and S.A.F.; data curation, S.I.B. and D.V.A.; Writing-Original Draft preparation, S.I.B. and D.V.A.; Writing-Review and Editing all authors; visualization, S.I.B., L.I.K. and D.V.A.; supervision, A.A.I. and S.I.B.

Funding: The study was funded by GZ-25/16 state assignment.

Conflicts of Interest: The authors declare no conflict of interest, financial or otherwise.

\section{References}

1. WHO Ebola Response Team; Agua-Agum, J.; Ariyarajah, A.; Aylward, B.; Blake, I.M.; Brennan, R.; Cori, A.; Donnelly, C.A.; Dorigatti, I.; Dye, C.; et al. West African Ebola epidemic after one year-Slowing but not yet under control. N. Engl. J. Med. 2015, 372, 584-587. [CrossRef] [PubMed]

2. Wong, G.; Qiu, X.; Olinger, G.G.; Kobinger, G.P. Post-exposure therapy of filovirus infections. Trends Microbiol. 2014, 22, 456-463. [CrossRef] [PubMed]

3. Saphire, E.O. An update on the use of antibodies against the filoviruses. Immunotherapy 2013, 5, 1221-1233. [CrossRef] [PubMed]

4. Lázaro-Frías, A.; Gómez-Medina, S.; Sánchez-Sampedro, L.; Ljungberg, K.; Ustav, M.; Liljeström, P.; Muñoz-Fontela, C.; Esteban, M.; García-Arriaza, J. Distinct Immunogenicity and Efficacy of Poxvirus-Based Vaccine Candidates against Ebola Virus Expressing GP and VP40 Proteins. J. Virol. 2018, 92. [CrossRef] [PubMed]

5. Rahim, M.N.; Wee, E.G.; He, S.; Audet, J.; Tierney, K.; Moyo, N.; Hannoun, Z.; Crook, A.; Baines, A.; Korber, B.; et al. Complete protection of the BALB/C and C57BL/6J mice against Ebola and Marburg virus lethal challenges by pan-filovirus T-cell epigraph vaccine. PLoS Pathog. 2019, 15, e1007564. [CrossRef]

6. Marzi, A.; Feldmann, H. Ebola virus vaccines: An overview of current approaches. Expert Rev Vaccines 2014, 13, 521-531. [CrossRef] [PubMed]

7. Henao-Restrepo, A.M.; Camacho, A.; Longini, I.M.; Watson, C.H.; Edmunds, W.J.; Egger, M.; Carroll, M.W.; Dean, N.E.; Diatta, I.; Doumbia, M.; et al. Efficacy and effectiveness of an rVSV-vectored vaccine in preventing Ebola virus disease: Final results from the Guinea ring vaccination, open-label, cluster-randomised trial (Ebola Ça Suffit!). Lancet 2017, 389, 505-518. [CrossRef]

8. Wu, L.; Zhang, Z.; Gao, H.; Li, Y.; Hou, L.; Yao, H.; Wu, S.; Liu, J.; Wang, L.; Zhai, Y.; et al. Open-label phase I clinical trial of Ad5-EBOV in Africans in China. Hum. Vaccin. Immunother. 2017, 13, 2078-2085. [CrossRef] 
9. Dolzhikova, I.V.; Zubkova, O.V.; Tukhvatulin, A.I.; Dzharullaeva, A.S.; Tukhvatulina, N.M.; Shcheblyakov, D.V.; Shmarov, M.M.; Tokarskaya, E.A.; Simakova, Y.V.; Egorova, D.A.; et al. Safety and immunogenicity of GamEvac-Combi, a heterologous VSV- and Ad5-vectored Ebola vaccine: An open phase I/II trial in healthy adults in Russia. Hum. Vaccin. Immunother. 2017, 13, 613-620. [CrossRef] [PubMed]

10. Shedlock, D.J.; Aviles, J.; Talbott, K.T.; Wong, G.; Wu, S.J.; Villarreal, D.O.; Myles, D.J.; Croyle, M.A.; Yan, J.; Kobinger, G.P.; et al. Induction of broad cytotoxic T cells by protective DNA vaccination against Marburg and Ebola. Mol. Ther. 2013, 21, 1432-1444. [CrossRef]

11. Krause, P.R.; Bryant, P.R.; Clark, T.; Dempsey, W.; Henchal, E.; Michael, N.L.; Regules, J.A.; Gruber, M.F. Immunology of protection from Ebola virus infection. Sci. Transl. Med. 2015, 7. [CrossRef]

12. Takada, A.; Ebihara, H.; Feldmann, H.; Geisbert, T.W.; Kawaoka, Y. Epitopes required for antibody-dependent enhancement of Ebola virus infection. J. Infect. Dis. 2007, 196 (Suppl. 2), S347-S356. [CrossRef]

13. Khan, K.H. DNA vaccines: Roles against diseases. Germs 2013, 3, 26-35. [CrossRef] [PubMed]

14. Lu, S.; Wang, S.; Grimes-Serrano, J.M. Current progress of DNA vaccine studies in humans. Expert Rev. Vaccines 2008, 7, 175-191. [CrossRef] [PubMed]

15. Grant-Klein, R.J.; Van Deusen, N.M.; Badger, C.V.; Hannaman, D.; Dupuy, L.C.; Schmaljohn, C.S. A multiagent filovirus DNA vaccine delivered by intramuscular electroporation completely protects mice from ebola and Marburg virus challenge. Hum. Vaccin. Immunother. 2012, 8, 1703-1706. [CrossRef] [PubMed]

16. Petkov, S.; Starodubova, E.; Latanova, A.; Kilpeläinen, A.; Latyshev, O.; Svirskis, S.; Wahren, B.; Chiodi, F.; Gordeychuk, I.; Isaguliants, M. DNA immunization site determines the level of gene expression and the magnitude, but not the type of the induced immune response. PLOS ONE 2018, 13, e0197902. [CrossRef]

17. Lambricht, L.; Lopes, A.; Kos, S.; Sersa, G.; Préat, V.; Vandermeulen, G. Clinical potential of electroporation for gene therapy and DNA vaccine delivery. Expert Opin. Drug Deliv. 2016, 13, 295-310. [CrossRef]

18. Karpenko, L.I.; Bazhan, S.I.; Eroshkin, A.M.; Antonets, D.V.; Chikaev, A.N.; Ilyichev, A.A. Artificial Epitope-Based Immunogens in HIV-Vaccine Design. Available online: https://www.intechopen.com/books/ advances-in-hiv-and-aids-control/artificial-epitope-based-immunogens-in-hiv-vaccine-design (accessed on 5 November 2018).

19. Öhlund, P.; García-Arriaza, J.; Zusinaite, E.; Szurgot, I.; Männik, A.; Kraus, A.; Ustav, M.; Merits, A.; Esteban, M.; Liljeström, P.; et al. DNA-launched RNA replicon vaccines induce potent anti-Ebolavirus immune responses that can be further improved by a recombinant MVA boost. Sci. Rep. 2018, 8, 12459. [CrossRef]

20. Bazhan, S.I.; Karpenko, L.I.; Ilyicheva, T.N.; Belavin, P.A.; Seregin, S.V.; Danilyuk, N.K.; Antonets, D.V.; Ilyichev, A.A. Rational design based synthetic polyepitope DNA vaccine for eliciting HIV-specific CD8+ T cell responses. Mol. Immunol. 2010, 47, 1507-1515. [CrossRef]

21. Hanke, T.; McMichael, A.J. Design and construction of an experimental HIV-1 vaccine for a year-2000 clinical trial in Kenya. Nat. Med. 2000, 6, 951-955. [CrossRef]

22. Karpenko, L.I.; Bazhan, S.I.; Antonets, D.V.; Belyakov, I.M. Novel approaches in polyepitope T-cell vaccine development against HIV-1. Expert Rev. Vaccines 2014, 13, 155-173. [CrossRef] [PubMed]

23. Khan, M.A.; Hossain, M.U.; Rakib-Uz-Zaman, S.M.; Morshed, M.N. Epitope-based peptide vaccine design and target site depiction against Ebola viruses: an immunoinformatics study. Scand. J. Immunol. 2015, 82, 25-34. [CrossRef] [PubMed]

24. Vita, R.; Overton, J.A.; Greenbaum, J.A.; Ponomarenko, J.; Clark, J.D.; Cantrell, J.R.; Wheeler, D.K.; Gabbard, J.L.; Hix, D.; Sette, A.; et al. The immune epitope database (IEDB) 3.0. Nucleic Acids Res. 2015, 43, D405-D412. [CrossRef] [PubMed]

25. Antonets, D.V.; Maksiutov, A.Z. TEpredict: software for T-cell epitope prediction. Mol. Biol. (Mosk.) 2010, 44, 130-139. [CrossRef] [PubMed]

26. Antonets, D.V.; Bazhan, S.I. PolyCTLDesigner: A computational tool for constructing polyepitope T-cell antigens. BMC Res. Notes 2013, 6, 407. [CrossRef] [PubMed]

27. Villalobos, A.; Welch, M.; Minshull, J. In silico design of functional DNA constructs. Methods Mol. Biol. 2012, 852, 197-213. [PubMed]

28. R Development Core Team. R: A Language and Environment for Statistical Computing. Vienna, Austria: The R Foundation for Statistical Computing. Available online: https://www.r-project.org/ (accessed on 22 March 2019). 
29. Karpenko, L.I.; Ilyichev, A.A.; Eroshkin, A.M.; Lebedev, L.R.; Uzhachenko, R.V.; Nekrasova, N.A.; Plyasunova, O.A.; Belavin, P.A.; Seregin, S.V.; Danilyuk, N.K.; et al. Combined virus-like particle-based polyepitope DNA/protein HIV-1 vaccine design, immunogenicity and toxicity studies. Vaccine 2007, 25, 4312-4323. [CrossRef] [PubMed]

30. Reguzova, A.; Antonets, D.; Karpenko, L.; Ilyichev, A.; Maksyutov, R.; Bazhan, S. Design and evaluation of optimized artificial HIV-1 poly-T cell-epitope immunogens. PLoS ONE 2015, 10, e0116412. [CrossRef] [PubMed]

31. Van de Weijer, M.L.; Luteijn, R.D.; Wiertz, E.J.H.J. Viral immune evasion: Lessons in MHC class I antigen presentation. Semin. Immunol. 2015, 27, 125-137. [CrossRef]

32. Yewdell, J.W. DRiPs solidify: Progress in understanding endogenous MHC class I antigen processing. Trends Immunol. 2011, 32, 548-558. [CrossRef]

33. Kutzler, M.A.; Weiner, D.B. DNA vaccines: Ready for prime time? Nat. Rev. Genet. 2008, 9, 776-788. [CrossRef] [PubMed]

34. Livingston, B.D.; Newman, M.; Crimi, C.; McKinney, D.; Chesnut, R.; Sette, A. Optimization of epitope processing enhances immunogenicity of multiepitope DNA vaccines. Vaccine 2001, 19, 4652-4660. [CrossRef]

35. Depla, E.; Van der Aa, A.; Livingston, B.D.; Crimi, C.; Allosery, K.; De Brabandere, V.; Krakover, J.; Murthy, S.; Huang, M.; Power, S.; et al. Rational design of a multiepitope vaccine encoding T-lymphocyte epitopes for treatment of chronic hepatitis B virus infections. J. Virol. 2008, 82, 435-450. [CrossRef] [PubMed]

36. Schubert, B.; Kohlbacher, O. Designing string-of-beads vaccines with optimal spacers. Genome Med. 2016, 8, 9. [CrossRef] [PubMed]

37. Uebel, S.; Wiesmüller, K.H.; Jung, G.; Tampé, R. Peptide libraries in cellular immune recognition. Curr. Top. Microbiol. Immunol. 1999, 243, 1-21.

38. Cardinaud, S.; Bouziat, R.; Rohrlich, P.-S.; Tourdot, S.; Weiss, L.; Langlade-Demoyen, P.; Burgevin, A.; Fiorentino, S.; van Endert, P.; Lemonnier, F.A. Design of a HIV-1-derived HLA-B07.02-restricted polyepitope construct. AIDS 2009, 23, 1945-1954. [CrossRef]

39. Schneider, S.C.; Ohmen, J.; Fosdick, L.; Gladstone, B.; Guo, J.; Ametani, A.; Sercarz, E.E.; Deng, H. Cutting edge: Introduction of an endopeptidase cleavage motif into a determinant flanking region of hen egg lysozyme results in enhanced T cell determinant display. J. Immunol. 2000, 165, 20-23. [CrossRef]

40. Zhu, H.; Liu, K.; Cerny, J.; Imoto, T.; Moudgil, K.D. Insertion of the dibasic motif in the flanking region of a cryptic self-determinant leads to activation of the epitope-specific T cells. J. Immunol. 2005, 175, 2252-2260. [CrossRef]

41. Varshavsky, A.; Turner, G.; Du, F.; Xie, Y. Felix Hoppe-Seyler Lecture 2000. The ubiquitin system and the N-end rule pathway. Biol. Chem. 2000, 381, 779-789. [CrossRef]

42. Rowell, J.F.; Ruff, A.L.; Guarnieri, F.G.; Staveley-O'Carroll, K.; Lin, X.; Tang, J.; August, J.T.; Siliciano, R.F. Lysosome-associated membrane protein-1-mediated targeting of the HIV-1 envelope protein to an endosomal/lysosomal compartment enhances its presentation to MHC class II-restricted T cells. J. Immunol. 1995, 155, 1818-1828.

43. Ruff, A.L.; Guarnieri, F.G.; Staveley-O'Carroll, K.; Siliciano, R.F.; August, J.T. The enhanced immune response to the HIV gp160/LAMP chimeric gene product targeted to the lysosome membrane protein trafficking pathway. J. Biol. Chem. 1997, 272, 8671-8678. [CrossRef] [PubMed]

44. Wu, T.C.; Guarnieri, F.G.; Staveley-O'Carroll, K.F.; Viscidi, R.P.; Levitsky, H.I.; Hedrick, L.; Cho, K.R.; August, J.T.; Pardoll, D.M. Engineering an intracellular pathway for major histocompatibility complex class II presentation of antigens. Proc. Natl. Acad. Sci. USA 1995, 92, 11671-11675. [CrossRef]

45. Guarnieri, F.G.; Arterburn, L.M.; Penno, M.B.; Cha, Y.; August, J.T. The motif Tyr-X-X-hydrophobic residue mediates lysosomal membrane targeting of lysosome-associated membrane protein 1. J. Biol. Chem. 1993, 268, 1941-1946. [PubMed]

46. Sette, A.; Sidney, J. HLA supertypes and supermotifs: a functional perspective on HLA polymorphism. Curr. Opin. Immunol. 1998, 10, 478-482. [CrossRef]

47. Sidney, J.; Grey, H.M.; Kubo, R.T.; Sette, A. Practical, biochemical and evolutionary implications of the discovery of HLA class I supermotifs. Immunol. Today 1996, 17, 261-266. [CrossRef]

48. Peters, B.; Bulik, S.; Tampe, R.; Van Endert, P.M.; Holzhütter, H.-G. Identifying MHC class I epitopes by predicting the TAP transport efficiency of epitope precursors. J. Immunol. 2003, 171, 1741-1749. [CrossRef] [PubMed] 
49. Toes, R.E.; Nussbaum, A.K.; Degermann, S.; Schirle, M.; Emmerich, N.P.; Kraft, M.; Laplace, C.; Zwinderman, A.; Dick, T.P.; Müller, J.; et al. Discrete cleavage motifs of constitutive and immunoproteasomes revealed by quantitative analysis of cleavage products. J. Exp. Med. 2001, 194,1-12. [CrossRef] [PubMed]

50. Bonehill, A.; Heirman, C.; Tuyaerts, S.; Michiels, A.; Breckpot, K.; Brasseur, F.; Zhang, Y.; Van Der Bruggen, P.; Thielemans, K. Messenger RNA-electroporated dendritic cells presenting MAGE-A3 simultaneously in HLA class I and class II molecules. J. Immunol. 2004, 172, 6649-6657. [CrossRef]

51. Bonini, C.; Lee, S.P.; Riddell, S.R.; Greenberg, P.D. Targeting antigen in mature dendritic cells for simultaneous stimulation of CD4+ and CD8+ T cells. J. Immunol. 2001, 166, 5250-5257. [CrossRef]

52. Kim, T.W.; Hung, C.-F.; Boyd, D.; Juang, J.; He, L.; Kim, J.W.; Hardwick, J.M.; Wu, T.-C. Enhancing DNA vaccine potency by combining a strategy to prolong dendritic cell life with intracellular targeting strategies. J. Immunol. 2003, 171, 2970-2976. [CrossRef]

53. Fassnacht, M.; Lee, J.; Milazzo, C.; Boczkowski, D.; Su, Z.; Nair, S.; Gilboa, E. Induction of CD4(+) and CD8(+) T-cell responses to the human stromal antigen, fibroblast activation protein: implication for cancer immunotherapy. Clin. Cancer Res. 2005, 11, 5566-5571. [CrossRef]

54. Petersen, T.N.; Brunak, S.; von Heijne, G.; Nielsen, H. SignalP 4.0: Discriminating signal peptides from transmembrane regions. Nat. Methods 2011, 8, 785-786. [CrossRef]

55. Deml, L.; Bojak, A.; Steck, S.; Graf, M.; Wild, J.; Schirmbeck, R.; Wolf, H.; Wagner, R. Multiple effects of codon usage optimization on expression and immunogenicity of DNA candidate vaccines encoding the human immunodeficiency virus type 1 Gag protein. J. Virol. 2001, 75, 10991-11001. [CrossRef]

(C) 2019 by the authors. Licensee MDPI, Basel, Switzerland. This article is an open access article distributed under the terms and conditions of the Creative Commons Attribution (CC BY) license (http://creativecommons.org/licenses/by/4.0/). 